\title{
Assessment of the Effect of Replacing Normal Aggregate by Porcelinite on the Behaviour of Layered Steel Fibrous Self-Compacting Reinforced Concrete Slabs under Uniform Load
}

\author{
Ahmed S. D. AL-Ridha $\mathbb{D D}^{1}{ }^{1}$ Ali A. Abbood, ${ }^{1}$ and Ali F. Atshan ${ }^{2}$ \\ ${ }^{1}$ Department of Civil Engineering, Mustansiriyah University, Baghdad 10001, Iraq \\ ${ }^{2}$ Department of Water Resources Engineering, Mustansiriyah University, Baghdad 10001, Iraq \\ Correspondence should be addressed to Ahmed S. D. AL-Ridha; ahmedsahibdiab@yahoo.com
}

Received 11 October 2019; Revised 28 January 2020; Accepted 12 February 2020; Published 11 March 2020

Academic Editor: İlker Bekir Topçu

Copyright (c) 2020 Ahmed S. D. AL-Ridha et al. This is an open access article distributed under the Creative Commons Attribution License, which permits unrestricted use, distribution, and reproduction in any medium, provided the original work is properly cited.

\begin{abstract}
In this research, an attempt has been made to study the effect of replacing all normal-weight aggregate "NWA" by lightweight aggregate "LWA" (having a volume equal to $60 \%$ of the volume of normal-weight aggregate) on the behaviour of layered steel fibrous self-compacting reinforced concrete slabs with various volume fractions of steel fiber under uniform area load using fine sand technique. The experimental work consists of two groups "NWA" and "LWA," each group consists of three slab specimens (having an aspect ratio equal to the golden ratio, i.e., 1.618), the thickness of each slab is divided into two equal layers, the top layer is free from steel fibers, while the steel fibers exist only in the bottom layer with three volume fractions $(0 \%, 0.4 \%$, and $0.8 \%)$. Ultimate uniform load of the slabs decreases with the increase in steel fiber content, while the percentage of decrease in the bulk density remains rather constant. It was also found that the ultimate uniform load of the slabs in each group is significantly improved with increasing steel fiber content, and the percentage of this improvement is higher in lightweight concrete "LWC" than in normal-weight concrete "NWC" Finally, it was noticed that when steel fiber increased, the flexural strength of slabs increased higher than shear strength; therefore, the mode of failure has been changed from bending to shear mode for slabs of both groups "NWC" and "LWC."
\end{abstract}

\section{Introduction}

The usage of the steel fibrous concrete (SFC) in the paving slabs industry is because of specified obstacles facing the reinforced concrete members. Actually, reinforcement can provide a distinguished solution in the control of cracking aspect of flooring slabs only when put in its correct position. The usage of fibers in the slab industry permits the transmission of forces throughout the side surfaces of cracks and then providing a ductile ambience to the concrete [1]. Since the dead weights of any structure represent the larger part of the total weights, the usage of lightweight concrete can highly decrease the weights of these structures, and hence, decreases the seismic loads and the contacting stresses between foundation and soil. By decreasing the weight of any building, considerable thrift in materials and constructional charges can also be accomplished. Moreover, the lightweight concrete elements have better insulation characteristics than normal-weight ones, in terms of noise and thermal insulation [2].

Lightweight concrete can be manufactured by the replacement of a part or a whole of natural normal-weight aggregate (NWA) by natural or artificial lightweight aggregate (LWA). The reduced flexural and tensile strength of (LWAC) may be attributed to the weakness of LWA. Brittleness of LWAC is converse with the basic target of LWAC that necessitates ductile conduct in earthquake analysis. This defect can be resolved by using adequate quantity of fiber [3-5]. The usage of fibers to strengthen brittle materials can be traced back to the age of Egyptians 
(about 5000 years ago) when asbestos fibers were used to reinforce clay pots [6]. However, the recent evolutions of fibrous concrete in the concrete industry have started in 1960 [7]. The most valuable characteristics of fibrous reinforced members are the improvement of bending strength, stiffness, postfailure flexibility, and control of cracking [8]. Lightweight aggregate has high absorption ability; thus, it is hard to estimate the quantity of water needed to accomplish a specified consistency. Furthermore, lightweight aggregate and because of their small density, they usually rise to the surface (during the mixing) causing reverse segregation. Lightweight concretes have a lower elastic modulus, larger creep, and more brittleness than normal-weight concrete [1]. Several investigators [1, 8-12] have used steel fiber to reinforce concrete. Others have used steel fiber to reinforce light-weight concrete $[2-5,10,11$, 13-15]. The rest of them have used self-compacting concrete in their researches, $[2,3,10,11,16,17]$. Al-Ridha [10] has studied the effect of lightweight aggregate size on the mechanical properties of self-compacting concrete with and without steel fibers. They have also studied the influence of steel fibers on the velocity of ultrasonic pulse of self-compacting lightweight concrete [11].

\section{Research Significance}

The objective of this research is to obtain lightweight reinforced concrete two-way slabs through replacing $60 \%$ of normal-weight aggregate volume by lightweight aggregate and strengthening them with steel fibers in order to compensate the weakness induced by such replacement as compared with the corresponding normal-weight ones. Furthermore, the present work has studied the technique of strengthening only the bottom half layer of the mentioned slabs (by steel fibers) in order to attain the best possible efficiency of steel fibers role by their least possible quantity used. Slab specimens in the current work were subjected to a uniformly distributed area load, and a new technique involves placing fine sand between the applied area load, and the slab specimen is used to ensure a perfectly uniform distribution of the load is maintained.

\section{Experimental Work}

\subsection{Materials}

3.1.1. Cement. The type of cement used for all concrete specimens throughout this research was Ordinary Portland (Type-I) local cement from "Tasluja" factory.

3.1.2. Sand (Normal Fine Aggregate). The sand (fine aggregate) that was chosen for the current study was brought from Al-Ukhaithir quarry. The sand particles have a rounded shape, a smooth surface, a $(4.75 \mathrm{~mm})$ maximum size with specific gravity 2.6 , and a fineness modulus of 2.84 . The results obtained from chemical and physical tests that were carried out for the used sand have pointed out that the grading and the sulfate content of the sand were within the acceptable limits of the Iraqi Specification No. 45/1984 [18].
The sand was exposed to dry air before being used in all concrete batches.

3.1.3. Gravel (Normal Coarse Aggregate). The gravel (coarse aggregates) used in this research were of round shape brought from the "AL-Niba'ai" region, having a specific gravity of 2.63 and a $(10 \mathrm{~mm})$ maximum size. The grading of the coarse aggregate was within the allowed limits set by ASTM-C33 specification [19], while its sulfate content was within the acceptable limits set by the Iraqi Specification no. $45 / 1984$ [18].

3.1.4. Additives (Superplasticizer). To increase the workability of the concrete mixes in our research, an additive called: "Sika-Visco-Cete-PC-20" was utilized as a superplasticizer with a dosage of 3.5 liter for each $100 \mathrm{~kg}$ of cement for all research mixes. This dosage was reached after several trial mixes, and this admixture was proved to improve the mix in the following aspects:

(i) A superior capability of water reduction, leading to large density, increased strength, and decreased water permeability

(ii) A supreme plasticizing behaviour, leading to an improved flow-ability, casting, and compacting ability

(iii) An excellent appropriateness for producing selfcompact concrete (S.C.C).

The characteristics of the utilized superplasticizer are listed in Table 1.

3.1.5. Steel Fibers. In this research, steel fibers of hooked ends which are commercially known as Dramex-Type-ZC were utilized. The characteristics of this steel fiber are listed in Table 2. This type of steel fiber differs from that used in [9] which has a length of $30 \mathrm{~mm}$, diameter of $0.5 \mathrm{~mm}$, and aspect ratio of 60 .

3.1.6. Mixing Water. The water that is utilized for mixing and curing of all concrete mixes in the present work was ordinary potable water.

3.1.7. Porcelinite. Porcelinite stone which is a natural local lightweight aggregate (LWA) is utilized as a lightweight coarse aggregate through the tests of lightweight concrete in this research. This stone was brought from a quarry located in "Trefawi" field (near Al-Rutba) at Iraqi western desert in Al-Anbar governorate. The needed amount of porcelinite stones is tested in the laboratories of the General Company of Geological Surveying and Mining.

This type of porcelinite rock is white in color and is generated fundamentally from opals, carbonates, and clays minerals [20]; therefore, it is described by high silicon oxide $\left(\mathrm{SiO}_{2}\right)$ content, high permeability, and low density.

Porcelinite masses are primarily smashed into smaller ones manually via a special maul in order to enable the stone 
TABLE 1: Characteristics of the superplasticizer.

\begin{tabular}{lcc}
\hline No. & Characteristic & Descriptions \\
\hline 1 & Commercially name & $\begin{array}{c}\text { Sika-visco-cete-PC-20 } \\
\text { Modify polycarboxylate-based }\end{array}$ \\
2 & Chemical basis & polymers \\
3 & Format & Fluid \\
4 & Color & Light brown \\
5 & Unit weight & $1.10-1.140 \mathrm{~kg} / \mathrm{lt}$ at $20 \mathrm{C}$ \\
6 & PH & $3-7$ \\
7 & Chloride & Without chloride \\
\hline
\end{tabular}

*Submitted by the industrialist.

Table 2: Properties of steel fibers*.

\begin{tabular}{lccc}
\hline $\begin{array}{l}\text { Commercial } \\
\text { name }\end{array}$ & $\begin{array}{c}\text { Geometric } \\
\text { shape }\end{array}$ & Property & Specifications \\
\hline Hooked ends & $\begin{array}{c}\text { Density } \\
\text { Maximum } \\
\text { strength } \\
\text { Elastic modulus } \\
\text { Strain at }\end{array}$ & $7860 \mathrm{~kg} / \mathrm{m}^{3}$ \\
Dramex-ZC & $\begin{array}{c}1131 \mathrm{MPa} \\
\text { proportional limit } \\
\text { Poisson's ratio } \\
\text { Average length }\end{array}$ & $5651 \times 0^{-6}$ \\
& $\begin{array}{c}\text { Nominal diameter } \\
\text { Aspect ratio } \\
\text { (Lf/Df) }\end{array}$ & 0.28 \\
& & $0.5 \mathrm{~mm}$ \\
& & 100 \\
\hline
\end{tabular}

*Supplied by the manufacturer.

masses inserting the feeding slot of the crushing machine. The "Jaws" crushing machine was set up to provide a final product having a maximum aggregate size of about $(10 \mathrm{~mm})$.

Tables 3-5 present the mineral, chemical, and physical properties obtained by the analyses that were carried out for porcelinite coarse LWA. Three sizes of porcelinite coarse LWA which satisfies the requirements of ASTM: C-330-2006 [23] were mixed to obtain the coarse aggregate in this study, as illustrated in Table 6 .

Due to their cellular structure, lightweight aggregates absorb more water than normal-weight aggregate and hence resulting in fast slump loss. Porcelinite aggregate is washed with water so as to clear the powder related with the crushing operation of porcelinite rocks since high rate of powder leads to segregate and causes crazing of the concrete mass (as recommended in [24]). "Porcelinite" aggregate was taken out and diffused far from sunlight for some time until aggregate granules become saturated dry surface (SDS). Until that, they are packaged in nylon sacks and stored in a special container as advised by ACI: 211.2-81 [25]. It is worthy to mention that other types of lightweight aggregates such as expanded clay called "Arlite" have been used by [13]; the main properties of this material are good insulation, porosity, and resistance.

3.1.8. Limestone Powder (LSP). This material (which is locally named as "Al-Ghubra") is a white fine limestone powder resulting from grinding lime stones that are excavated from different regions in Iraq by blowing technique.
TABle 3: Mineral analysis of lightweight (porcelinite) aggregate.*

\begin{tabular}{lc}
\hline Composition & Percentage (by weight) (\%) \\
\hline Quartzite & 10.5 \\
Opal-CT & 65.1 \\
Clay & 7.72 \\
Dolomites & 7.16 \\
Gypsum & 0.60 \\
Apatite & 1.85 \\
Halite & 0.65 \\
Calcite & 6.25 \\
\hline
\end{tabular}

${ }^{*}$ Mineral analysis submitted by the General Company of Geological Surveying and Mining.

TABLE 4: Chemical analysis of lightweight porcelinite aggregate*.

\begin{tabular}{lc}
\hline Oxides & Percentage (by weight) \\
\hline $\mathrm{AL}_{2} \mathrm{O}_{3}$ & 0.63 \\
$\mathrm{CaO}$ & 12.05 \\
$\mathrm{Fe}_{2} \mathrm{O}_{3}$ & 0.38 \\
$\mathrm{MgO}$ & 0.56 \\
$\mathrm{SO}_{3}$ & 0.30 \\
$\mathrm{SiO}_{2}$ & 74.71 \\
$\mathrm{TiO}_{2}$ & 0.05 \\
$\mathrm{CL}$ & 0.07 \\
Ignition loss & 5.1 \\
${ }^{*}$ Chemical and physical analyses submitted by the General Company of \\
Geological Surveying and Mining.
\end{tabular}

TABLe 5: Physical characteristics of porcelinite coarse-aggregate.

\begin{tabular}{lcc}
\hline Property & Testing result & Specifications \\
\hline $\begin{array}{l}\text { Specific gravity } \\
\begin{array}{l}\text { Dry loose density } \\
\left(\mathrm{kg} / \mathrm{m}^{3}\right)\end{array}\end{array}$ & 1.53 & ASTM-C-127-2000 [21] \\
$\begin{array}{l}\text { Rodded-dry } \\
\left(\text { density kg/m } \mathrm{m}^{3}\right)\end{array}$ & 635 & ASTM-C-29/C 29M-17a [22] \\
Absorption $(\%)$ & 33.9 & ASTM-C-29/C 29M-17a [22] \\
\hline
\end{tabular}

TABLE 6: Grading of coarse porcelinite aggregate.

\begin{tabular}{lcccc}
\hline $\begin{array}{l}\text { Porcelinite } \\
\text { aggregate } \\
\text { size }(\mathrm{mm})\end{array}$ & (\%) Using & $\begin{array}{c}\text { Sieve } \\
\text { size } \\
(\mathrm{mm})\end{array}$ & $\begin{array}{c}\text { Accumulative } \\
(\%) \text { passing }\end{array}$ & $\begin{array}{c}\text { Accumulative } \\
\text { (\%) passing } \\
\text { (ASTM C-330) }\end{array}$ \\
\hline $12.6>S>9.5$ & 15 & 12.5 & 100 & 100 \\
$9.5>S>4.75$ & 55 & 9.5 & 85 & $80-100$ \\
$S<4.75$ & 30 & 4.75 & 30 & $5-40$ \\
\hline
\end{tabular}

This filler material is used in many aspects in the construction field here in Iraq.

\section{Concrete Mixes}

Two types of concrete mixes were studied, according to the density of coarse aggregate (lightweight or normal weight) and the volumetric fractions of the induced steel fiber, the following mixes were used: 
(i) Mixes of normal weight concrete that contain normal-weight sand, normal-weight gravel (natural river gravel), and steel fibers with three volumefractions $\left(V_{f}\right):(0 \%),(0.4 \%)$, and $(0.8 \%)$

(ii) Mixes of lightweight concrete which contain normal-weight sand and lightweight coarse (porcelinite) aggregate (obtained by replacing all normal-weight aggregate by lightweight aggregate having a volumetric ratio equals $(60 \%)$ of normal weight coarse aggregate) and steel fibers with three volume-fractions $\left(V_{\mathrm{f}}\right):(0 \%),(0.4 \%)$, and $(0.8 \%)$.

4.1. Mixing Proportions. To produce a nonfibrous concrete (lightweight or normal-weight), the mixing proportions (by weight) used for normal-weight concrete in this work (cement: filler: sand: normal-weight aggregate) was $1: 0.1$ : 1.9:2 and for lightweight concrete (cement: filler: sand: lightweight aggregate), it was $1: 0.1: 1.9: 0.94$, the water/ cement ratio was taken to be 0.44 , and the dosage of the superplasticizer agent was $3.5 \%$ of cement weight. This mix proportion was determined after numerous trial mixes to find the most appropriate one.

In the present work, the difference between the two types of the produced mixes is based on the type of coarse aggregate (normal-weight or lightweight) used. The volume of lightweight aggregate (porcelinite coarse aggregate) substituent to normal-weight aggregate (natural river gravel) was about $60 \%$ of its total volume.

The following equation was used to compute the corresponding weight of lightweight aggregate which has a volume equal to $60 \%$ of normal-weight aggregate volume:

$$
W_{L}=Q \times\left[\frac{\mathrm{SG}_{L}}{\mathrm{SG}_{N}} \times W_{N}\right] \times(1+A),
$$

where $Q$ is the replacement reduction factor $=60 \%, \mathrm{SG}_{L}$ is the specific gravity of lightweight aggregate, $\mathrm{SG}_{N}$ is the specific gravity of normal-weight aggregate, $W_{N}$ is the weight of normal-weight aggregate (natural river gravel), $W_{L}$ is the weight of lightweight aggregate (porcelinite coarse aggregate), and $\mathrm{A}$ is the absorption percentage of lightweight aggregate (\%).

Steel fiber-reinforced concrete (SFRC) was produced by scattering steel fibers (with the selected quantity) to the fresh nonfibrous concrete. Three types of steel fiber-reinforced concrete mixtures are used in this research according to their steel fiber content $0 \%, 0.4 \%$, or $0.8 \%$ used in each type.

The mix proportions have a tendency to follow British expertise which generally adopts a large rate of sand (exceeding $50 \%$ of aggregate weight) with maximum size of aggregate $(10 \mathrm{~mm})$ [26]. The flow-ability of the mix and the uniform spread of the steel fibers are significant parameters that the features of fibrous concrete depend upon.

4.2. Mixing Procedure. In order to obtain a self-compacting concrete satisfying the criteria of passing-ability, fillingability, and resistance to segregation, the mixing procedure is a considerable parameter. Since a good dispersal of fibers precludes fiber lumping, the concrete in this work was mixed manually using a pan of which the internal surface is cleaned and moistened before placing the constituent materials. To have steel fibers uniformly distributed and prevent lumping, the needed quantity of steel fibers was scattered manually to the mix to ensure a good dispersal of steel fibers, and a homogeneous fresh concrete was obtained. The mixing procedure is clearly described in the points below:

(i) At first, sand, limestone, and gravel were poured into the pan and mixed for few minutes, and later on, the cement is added to the mix. Then, materials are remixed until getting a uniform mixture.

(ii) Since the $w / c$ ratio in this research is 0.44 , i.e., $w=0.44 \mathrm{C}$, the total amount of water $(w)$ is divided into two quantities (i.e., $w=w_{1}+w_{2}$ ) where $w_{1}=0.4 \mathrm{C}$ and $w_{2}=0.04 \mathrm{C}$.

(iii) $50 \%$ of $w_{1}$ was poured to the mix, and the compositions were remixed for several minutes.

(iv) Afterwards, the superplasticizer agent was mixed with $20 \%$ of $w_{1}$, and they were poured together into the mix and remixed.

(v) Thereafter, the residual $30 \%$ of $\left(w_{1}\right)$ were added to the mix and remixed again until a uniform fresh mix is resulted.

(vi) At last, the remaining quantity of water $\left(w_{2}\right)$ was added and remixed.

For the mixes that contain steel fiber, the needed quantity of steel fibers was manually scattered to the mix to prevent lumping and to make steel fibers uniformly distributed throughout the fresh concrete.

\subsection{Reinforced Concrete Slabs}

4.3.1. Details of the Tested Slabs. The testing plan include testing six reinforced concrete slabs with mold outer dimensions of $427 \mathrm{~mm}$ width $\times 660 \mathrm{~mm}$ length $\times 40 \mathrm{~mm}$ thickness and net dimensions of $a=377 \mathrm{~mm}$ (width), $b=610 \mathrm{~mm}$ (length), and $h=40 \mathrm{~mm}$ (thickness), which result in $b / a=610 / 377=1.618=($ golden ratio $):[(1+\sqrt{5}) / 2]$ [27].

These slabs were arranged into two groups. The first group contains three slabs of normal-weight coarse aggregate, denoted by $\mathrm{N}, 4 \mathrm{~F}$, and $8 \mathrm{~F}$ referring to the three steel fiber volume-fractions: $0 \%, 0.4 \%$, and $0.8 \%$, respectively.

The second group contains three slabs of lightweight coarse aggregate denoted by $L, 4 \mathrm{FL}$, and $8 \mathrm{FL}$ (produced by replacing all normal-weight coarse aggregate by lightweight coarse aggregate of a volume equal to $60 \%$ of normal-weight aggregate volume) and also contains three volume-fractions of steel fiber: $0 \%, 0.4 \%$, and $0.8 \%$, respectively.

4.3.2. Details of the Mold. Figure 1 illustrates the wooden form used in the fabrication of all concrete slabs (normal weight and light weight). They are made from $18 \mathrm{~mm}$ thick plywood with following inner dimensions: $b=660 \mathrm{~mm}$ length, $a=427 \mathrm{~mm}$ width, and $h=40 \mathrm{~mm}$ thickness. In 


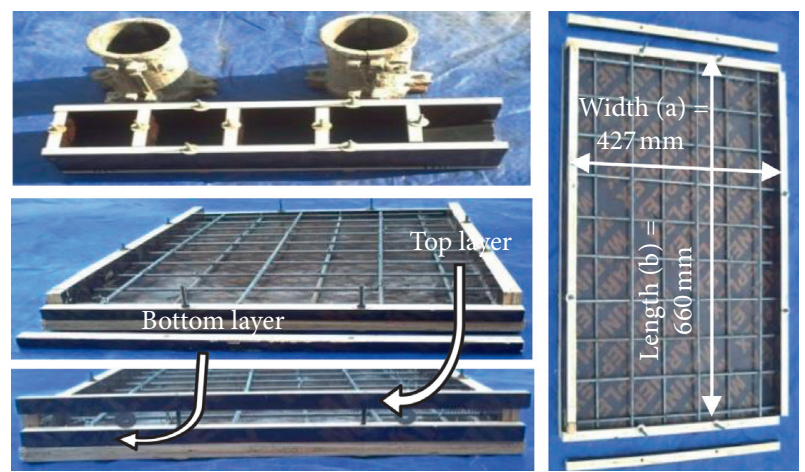

FIGURE 1: Details of the forms used for slabs, cubes, and cylinders.

addition, $100 \mathrm{~mm}$ cubic wooden forms and $100 \times 200 \mathrm{~mm}$ steel cylinders were used for the control specimens.

4.3.3. Steel Reinforcement Details. Deformed bars with a nominal diameter of $(5 \mathrm{~mm})$ were used to reinforce all concrete slabs; they were used as a mesh with center to center spacing of $70 \mathrm{~mm}$ in each direction. The bars parallel to the width were arranged in a reciprocal sequence above and below the bars parallel to the length. This kind of layout is selected so that the effective depth $(d)$ becomes equal in both directions as illustrated in Figure 2. All deformed bars have $F_{\mathrm{y}}=708 \mathrm{MPa}$ and $F_{\mathrm{u}}=1164 \mathrm{MPa}$ found after executing a direct tension test of a steel bar specimen according to ASTM A370-2014 [28] using the hydraulic universal machine with a capacity of $1200 \mathrm{kN}$ carried out at the laboratory of civil engineering department in the college of engineering at Mustansiriyah University. This same machine and specification was also used for the tensile test of the plate specimen of the researches $[29,30]$, and all bars were tied together using $(1 \mathrm{~mm})$ steel wire.

4.3.4. Fabrication and Curing Details. Before casting, the wooden form is cleaned and oiled. Then, the prepared reinforcing mesh is placed horizontally using five supports one in each corner and in the center to provide a $2 \mathrm{~mm}$ concrete protection cover. All slabs were casted due to the procedure of mixing described before. After pouring the fresh concrete into the slab wooden form and into the control specimens' mold (cylinders and cubes), they were knocked by a special hammer from all directions of the mold in order to provide enough vibration until casting was finished. Then, the wooden forms were wrapped by a nylon membrane to preclude water evaporation. One day later, the control specimens and the slabs were taken off the molds for the curing process in a bath of water for about 30 days. To retain the temperature of the water bath at about $25^{\circ} \mathrm{C}$ to $30^{\circ} \mathrm{C}$, two heaters (which are basically used for fish ponds) were modified to suit our work; besides, a suitable water pump is also used to distribute the heat all over the water bath. After 30 days, the specimens were taken out of the water bath in order to be tested.

4.4. Testing Procedure. Figure 3 shows the details of the testing frame on which concrete slabs were put to be tested.

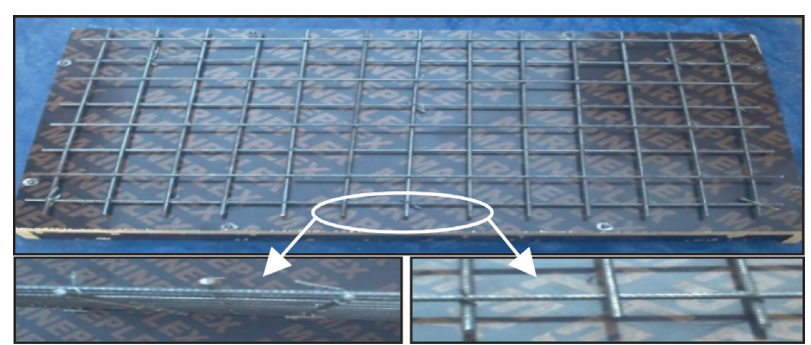

FIGURE 2: Details of the reinforcement mesh used for concrete slabs.

Slab specimens were placed on the steel frame which is located under the testing machine. Mold edges were fixed so that the supports centerlines, machine loads on the distribution load plate, and dial gauges were located at their correct positions. Fine sand is put between the loading plate and the slab specimens to ensure a perfect uniform distribution of the plate load over the whole area of the slab specimen. Loading was applied in small increments of $(2 \mathrm{kN})$, i.e., pressure increment is $2 \mathrm{kN} /(0.61 \mathrm{~m} \times 0.377 \mathrm{~m})=$ $8.7 \mathrm{KPa}$. At each loading stage, the readings of deflection at midspan and at the rubber support edges were recorded so that the correct deflection at the slab center is the difference between the two. The loading increments remain applied even after the first crack appeared since the width and depth of the cracks were gradually increased with the increase of pressure until failure is reached.

\section{Experimental Results}

The sections below display the results of the conventional tests that were implemented for the fresh and the hardened concrete.

5.1. Slump-Flow and T-50 Tests. This test is established to evaluate the horizontal free flow of self-compact concrete (SCC). It is the most popular test that provides a proper evaluation of filling-ability. It may also provide some significance to segregation resistance of (SCC) to an experienced user [12]. "T-50 test" gives also a measurement of flow pace and thus the consistency of (SCC) [17] This test was originally evolved in Japan to test the underwater and the highly flowable concretes [12].

Table 7 illustrates the results of slump-flow and T-50 cm tests. The $D$ values refer to the maximum spread (i.e., the ultimate diameter of slump flow), while the T-50 values refer to the required time for the concrete flow to reach a circle of $(50 \mathrm{~cm})$ diameter (Figure 4). Table 7 reveals that the results were within the accepted limits set by the acceptance criteria for self-compact concrete [31] and clearly shows that the filling ability is reduced when steel fibers are added to the concrete mix.

\subsection{Tests of Hardened Concrete}

5.2.1. Compressive Strength. The compressive strength test was performed according to BS-1881: part-116: 1989 [32] 

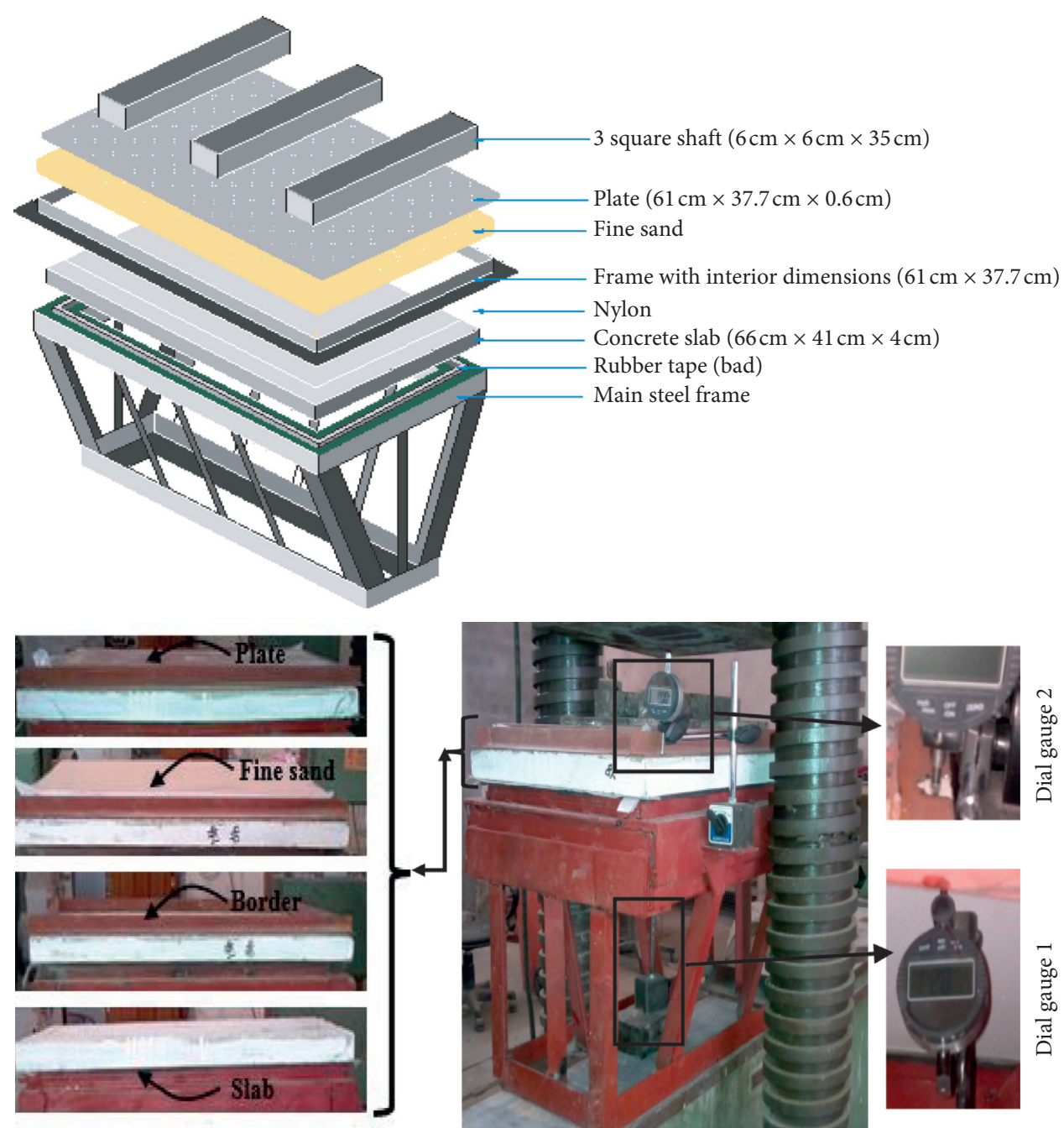

FIgURE 3: Setup on which slab specimens are tested.

TABLE 7: Slump-flow test and acceptance criteria for self-compact concrete.

\begin{tabular}{|c|c|c|c|c|c|c|c|}
\hline Concrete type & $V f(\%)$ & $D(\mathrm{~mm})$ & T-50 (sec.) & \multicolumn{4}{|c|}{ Acceptance criteria for self-compact concrete } \\
\hline \multirow{3}{*}{ Normal weight } & 0 & 630 & 6 & \multicolumn{4}{|c|}{ Typical values range } \\
\hline & 0.4 & 620 & 7 & \multirow{2}{*}{$\begin{array}{l}\text { Slump-flow by } \\
\text { Max. } D(\mathrm{~mm})\end{array}$} & \multirow{2}{*}{$\begin{array}{l}\text { Abrams cone } \\
\text { Min. } D(\mathrm{~mm})\end{array}$} & \multicolumn{2}{|c|}{ T-50 slump-flow } \\
\hline & 0.8 & 610 & 9 & & & Max. T-50 (sec.) & Min. T-50 (sec.) \\
\hline \multirow{3}{*}{ Light weight } & 0 & 645 & 4 & \multirow{3}{*}{800} & \multirow{3}{*}{600} & \multirow{3}{*}{25} & \multirow{3}{*}{3} \\
\hline & 0.4 & 625 & 5 & & & & \\
\hline & 0.8 & 620 & 6 & & & & \\
\hline
\end{tabular}
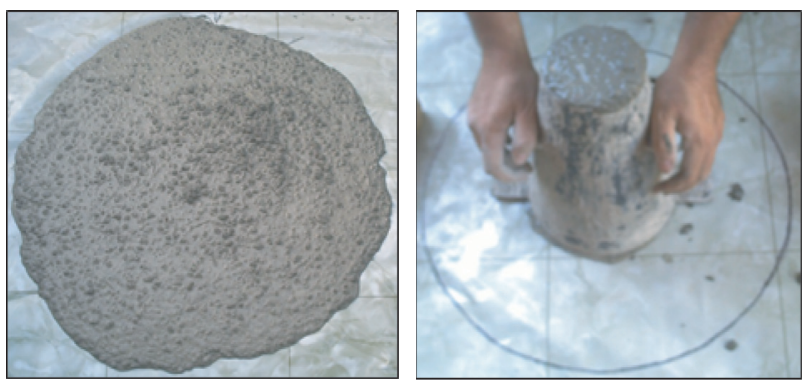

FIgURE 4: Slump-flow test.
The specimens are $(100 \mathrm{~mm})$ cubes, and they were tested using the $(2000 \mathrm{kN}$ capacity) electrical testing machine.

5.2.2. Splitting-Tensile Strength. The splitting-tensile strength test was carried out according to ASTM-C-496/C496M-17 [33]. The tested specimens are $100 \times 200 \mathrm{~mm}$ cylinders.

5.2.3. Density (Unit: Weight). The density of two types of concrete (normal weight and light weight) with the three volume-fractions of steel fibers, $0 \%, 0.4 \%$, and $0.8 \%$, were 
measured using the apparatus shown in Figure 5, and the results were computed using the following formula:

$$
\text { Density }=\frac{W_{A}}{\left(W_{A}-W_{W}\right) / \gamma_{W}},
$$

where = the weight in air, $W_{W}=$ the weight in water, and $\gamma_{w}=$ the mass density of water.

Table 8 illustrates the effect of increasing steel fiber contents on the abovementioned mechanical properties for the two types of concrete (normal weight and light weight). The results of the current study revealed that the increase in steel fiber content has a slight effect in density. The same outcome is reported by Libre et al. [14]; while they showed that the increasing of steel fiber content has made a significant increase in the compressive strength. In fact, all previous studies generally reach the same conclusion as this study reaches although some studies have found that the insertion of steel fiber by more than $2 \%$ content may decrease it [15]. Besides, the effect of increasing steel fiber led to a considerable improvement in splitting-tensile strength.

Moreover, one can notice from Table 8 that when steel fibers are added to normal- and lightweight concretes with two contents $(0.4 \%$ and $0.8 \%)$, the percentage of increase in the compressive and split-tensile strengths for the normalweight (aggregate) concrete is higher than that for lightweight (aggregate) concrete.

This behaviour in the compression test may be because the failure in lightweight concrete occurs in the lightweight aggregates themselves (which are the weakest points in the concrete mass), and hence the effectiveness of adding steel fibers in lightweight concrete became smaller than in normal-weight concrete.

As for the split-tensile test, the behaviour could be attributed to the fact that the addition of steel fibers in lightweight concrete increases the tensile strength higher than the bearing capacity of the concrete against the applied compressive force which leads to crush the two upper and lower surfaces attaching the applied load because of the presence of lightweight aggregate leading to deteriorate the tensile strength (represented by the appearance of a vertical crack at the circular cross section of the cylindrical sample) to less than its supposed value, as obviously seen in Figure 6(a). While in Figure 6(b), which represents a lightweight concrete without steel fibers, one can obviously see the splitting of the cylinder without any compressive crushing in the upper and lower surfaces, and hence the effectiveness of adding steel fibers in lightweight concrete is also smaller than in normal-weight concrete.

For the density and since the same amount of steel fibers is added to both normal and lightweight concretes, it is axiomatic that the percentage of increase in density of lightweight concrete is higher than that of normal-weight concrete when equal weight of steel fibers is added to both.

Table 9 displays the replacement effect of normal-weight by lightweight aggregate (in the cubic and cylindrical samples) on the compressive strength, splitting tensile strength, and density with various steel fiber contents. This table reveals that this replacement leads to deterioration of

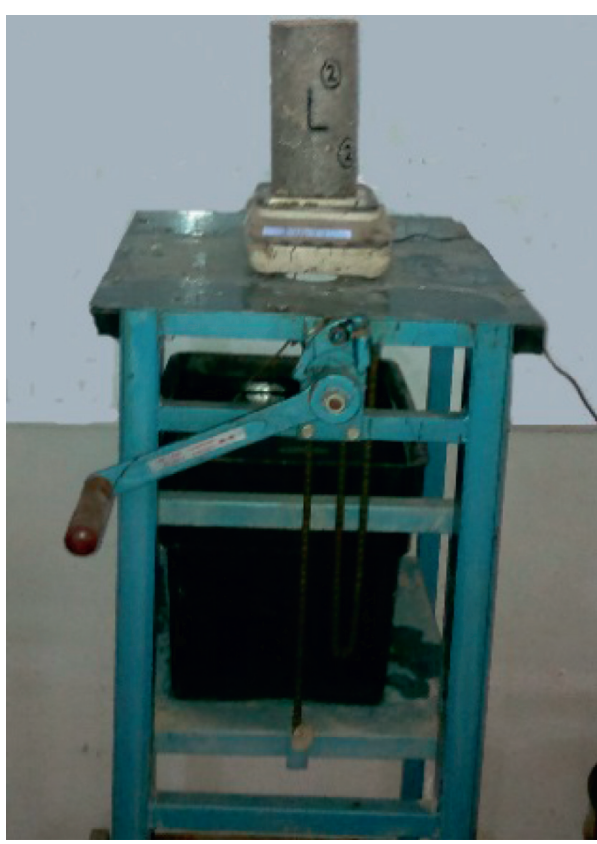

Figure 5: Apparatus of the density test.

the compressive and split-tensile strengths, and the percentage of this deterioration increases with the presence of steel fiber; the reason for this behaviour might be because the percentage of increase in the compressive and split-tensile strengths when steel fibers are added to the mix is higher in normal than in lightweight concrete as mentioned in the previous paragraph.

As for the density, Table 9 also shows that the replacing of normal-weight aggregate by lightweight lead also to reduce the density, but the percentage of this decrease is reduced with the presence of steel fibers; the reason for this behaviour may be because the percentage of increase in the density when steel fibers are added is higher in light than in normal-weight concrete as previously mentioned.

\section{Experimental Results for Concrete Slabs}

6.1. Effect of Steel Fiber Content on Ultimate Uniform Load. Figure 7 shows the effect of increasing steel fiber volume fraction $\left(V_{f}\right): 0 \%, 0.4 \%$, and $0.8 \%$ on the ultimate uniform load of concrete slab of groups (1) and (2) having normalweight and lightweight aggregates, respectively.

Table 10 shows the percentage of increases in the ultimate uniform load with increasing steel fiber content as compared with reference slabs $N$ and $L$ for normal-weight and lightweight aggregates, respectively. This table also reveals that the ultimate uniform load is significantly increased when the steel fiber content increases, and the percentage of increase in ultimate uniform load values is slightly higher in lightweight concrete slabs than in normal-weight concrete slabs.

The increase in the ultimate uniform load of fibrous slabs (of normal-weight and lightweight aggregate) may be imputed to the role of steel fibers in improving the capability of concrete in resisting more bending and shear effects. 
TABLE 8: Effect of steel fiber volume fraction $\left(V_{f}\right)$ on splitting tensile strength, compressive strength, and density of normal-weight and lightweight concretes.

\begin{tabular}{|c|c|c|c|c|c|c|c|}
\hline Concrete type & $V_{f}(\%)$ & $f_{t}(\mathrm{MPa})$ & Percentage of increase & $f_{\mathrm{cu}}(\mathrm{MPa})$ & Percentage of increase & Density $\left(\mathrm{kg} / \mathrm{m}^{3}\right)$ & Percentage of increase \\
\hline \multirow{3}{*}{ Normal weight } & 0 & 3.2 & - & 30.5 & - & 2336 & - \\
\hline & 0.4 & 4.3 & 34.3 & 35.5 & 16.3 & 2377 & 1.7 \\
\hline & 0.8 & 5.3 & 65.6 & 38.1 & 24.9 & 2405 & 2.9 \\
\hline \multirow{3}{*}{ Light weight } & 0 & 2.4 & - & 19 & - & 2008 & - \\
\hline & 0.4 & 3.0 & 25 & 21.3 & 12.1 & 2045 & 1.8 \\
\hline & 0.8 & 3.7 & 54.1 & 23.5 & 23.6 & 2080 & 3.5 \\
\hline
\end{tabular}

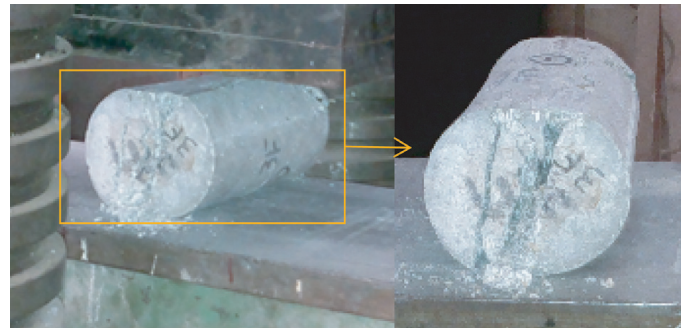

(a)

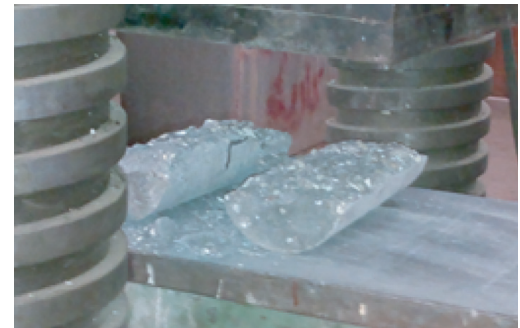

(b)

FIGURE 6: Failure of lightweight cylinders after splitting tensile test (a) with and (b) without steel fiber.

TABLE 9: Effect of replacing normal-weight aggregate by lightweight aggregate on the splitting-tensile strength, compressive strength, and density with various $\left(V_{f}\right)$ values.

\begin{tabular}{lccccccc}
\hline Concrete type & $V_{f}(\%)$ & $f_{t}(\mathrm{MPa})$ & Percentage of decrease & $f_{\mathrm{cu}}(\mathrm{MPa})$ & Percentage of decrease & Density $\left(\mathrm{kg} / \mathrm{m}^{3}\right)$ & Percentage of decrease \\
\hline Normal weight & 0 & 3.2 & - & 30.5 & - & 2336 & - \\
Light weight & 0 & 2.4 & 25 & 19 & 37.7 & 2008 & 14 \\
Normal weight & 0.4 & 4.3 & - & 35.5 & - & 2377 & - \\
Light weight & 0.4 & 3.0 & 30.2 & 21.3 & - & 2045 & 13.9 \\
Normal weight & 0.8 & 5.3 & - & 38.1 & 38.3 & 2405 & - \\
Light weight & 0.8 & 3.7 & 30.18 & 23.5 & & & 13.5 \\
\hline
\end{tabular}

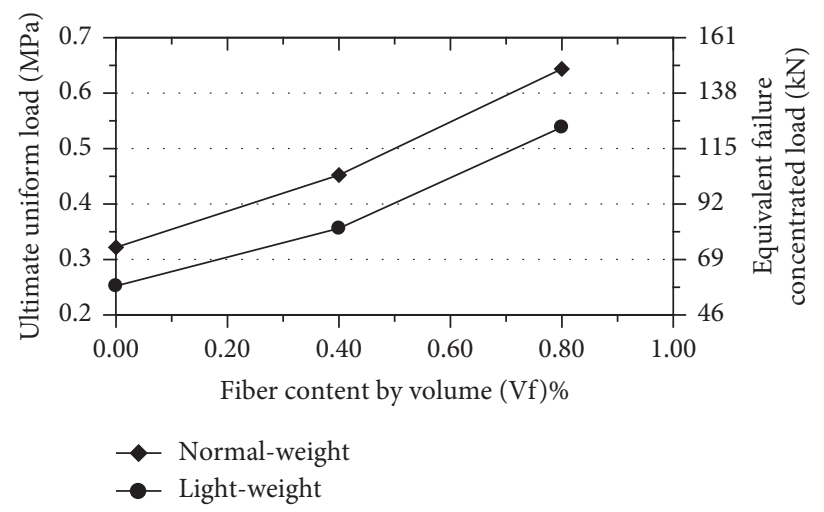

FIGURE 7: Effect of steel fiber volume fraction $\left(V_{f}\right) \%$ on the ultimate uniform load of (normal-weight and lightweight) concrete slabs.

The higher percentages of increase in ultimate uniform load when adding steel fibers to concrete slabs (ofnormalweight and lightweight aggregates) may also be imputed to the gradient of steel fibers, since almost all of steel fibers (of any horizontal orientation) had a small vertical slope because of the small slab thickness.

Moreover, one can notice from Tables 10 and 11 that the percentage of increase in ultimate uniform load applied to the lightweight slab when steel fibers are added is higher than that in normal-weight slab; this behaviour might be attributed to the fact that lightweight concrete is a rather weak material, and the effect of the adding steel fibers to it is higher than that for normal-weight concrete especially at the regions where potential shear or tension cracks exist. When steel fibers are placed in only the bottom layer of the slab, then it will work to prevent or minimize the initiation of 
TABLE 10: Effect of steel fiber content $\left(V_{f}\right) \%$ on ultimate uniform load for -normal and lightweight concrete slabs.

\begin{tabular}{|c|c|c|c|c|c|c|c|c|c|}
\hline Designation & $\begin{array}{c}\text { Layer } \\
\text { designation }\end{array}$ & $\begin{array}{l}\mathrm{Vf} \\
(\%)\end{array}$ & $\begin{array}{c}f_{\mathrm{cu}} \\
(\mathrm{MPa})\end{array}$ & $\begin{array}{c}f_{t} \\
\mathrm{MPa}\end{array}$ & $\begin{array}{l}\text { Density } \\
\left(\mathrm{kg} / \mathrm{m}^{3}\right)\end{array}$ & $\begin{array}{l}P u^{*} \\
(\mathrm{kN})\end{array}$ & $\begin{array}{l}\text { Ultimate uniform load } \\
\qquad(\mathrm{MPa})\end{array}$ & $\begin{array}{l}\text { Percentage of } \\
\text { increase }\end{array}$ & \\
\hline$N$ & All layers & 0 & 30.5 & 3.2 & 2336 & 74 & 0.321781 & - & \multirow{5}{*}{$\begin{array}{l}\text { Normal } \\
\text { weight }\end{array}$} \\
\hline \multirow{2}{*}{$N / 4 F$} & Top layer & 0 & 30.5 & 3.2 & 2336 & 104 & 0.452233 & 40.5 & \\
\hline & Bottom layer & 0.4 & 35.5 & 4.3 & 2377 & & & & \\
\hline \multirow{2}{*}{$N / 8 F$} & Top layer & 0 & 30.5 & 3.2 & 2336 & 148 & 0.643562 & 100 & \\
\hline & Bottom layer & 0.8 & 38.1 & 5.3 & 2405 & & & & \\
\hline $\bar{L}$ & All layers & 0 & 19 & 2.4 & 2008 & 58 & 0.252207 & - & \multirow{5}{*}{ Light weight } \\
\hline \multirow{2}{*}{$L / 4 \mathrm{FL}$} & Top layer & 0 & 19 & 2.4 & 2008 & 82 & 0.356015 & 41.3 & \\
\hline & Bottom layer & 0.4 & 21.3 & 3.0 & 2045 & & & & \\
\hline \multirow{2}{*}{$L / 8 \mathrm{FL}$} & Top layer & 0 & 19 & 2.4 & 2008 & 124 & 0.538365 & 113.8 & \\
\hline & Bottom layer & 0.8 & 23.5 & 3.7 & 2080 & & & & \\
\hline
\end{tabular}

*Equivalent failure concentrated load.

TABLE 11: Effect of replacing normal-weight aggregate by lightweight aggregate on ultimate uniform load and density.

\begin{tabular}{|c|c|c|c|c|c|c|c|c|c|c|}
\hline Designation & $\begin{array}{c}\text { Layer } \\
\text { designation }\end{array}$ & $\begin{array}{c}V_{f} \\
(\%)\end{array}$ & $\begin{array}{c}f_{\mathrm{cu}} \\
(\mathrm{MPa})\end{array}$ & $\begin{array}{c}f_{t} \\
(\mathrm{MPa})\end{array}$ & $\begin{array}{l}\text { Density } \\
\left(\mathrm{kg} / \mathrm{m}^{3}\right)\end{array}$ & $\begin{array}{c}\text { Percentage of } \\
\text { decrease }\end{array}$ & $\begin{array}{l}\mathrm{Pu}^{* *} \\
(\mathrm{kN})\end{array}$ & $\begin{array}{c}\text { Ultimate } \\
\text { uniform load } \\
(\mathrm{MPa})\end{array}$ & $\begin{array}{c}\text { Percentage of } \\
\text { decrease }\end{array}$ & \\
\hline$N$ & All layers & 0 & 30.5 & 3.2 & 2336 & - & 74 & 0.321781 & - & \multirow{2}{*}{$V_{f}=0 \%$} \\
\hline$L$ & All layers & 0 & 19 & 2.4 & 2008 & 14.04 & 58 & 0.252207 & 21.62 & \\
\hline \multirow{2}{*}{$N / 4 F$} & Top layer & 0 & 30.5 & 3.2 & 2336 & - & 104 & 0.452233 & 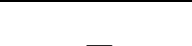 & \multirow{4}{*}{$V_{f}=0.4 \%$} \\
\hline & Bottom layer & 0.4 & 35.5 & 4.3 & 2377 & & & & \multirow{3}{*}{21.15} & \\
\hline \multirow{2}{*}{$L / 4 \mathrm{FL}$} & Top layer & 0 & 19 & 2.4 & 2008 & $14^{*}$ & 82 & 0.356015 & & \\
\hline & Bottom layer & 0.4 & 21.3 & 3.0 & 2045 & & & & & \\
\hline \multirow{2}{*}{$N / 8 F$} & Top layer & 0 & 30.5 & 3.2 & 2336 & - & 148 & 0.643562 & & \multirow{4}{*}{$V_{f}=0.8 \%$} \\
\hline & Bottom layer & 0.8 & 38.1 & 5.3 & 2405 & & & & 一 & \\
\hline \multirow{2}{*}{$L / 8 \mathrm{FL}$} & Top layer & 0 & 19 & 2.4 & 2008 & $13.77^{*}$ & 124 & 0.538365 & 16.21 & \\
\hline & Bottom layer & 0.8 & 23.5 & 3.7 & 2080 & & & & & \\
\hline
\end{tabular}

${ }^{*}$ Use the average value. ${ }^{* *}$ Equivalent failure concentrated load.
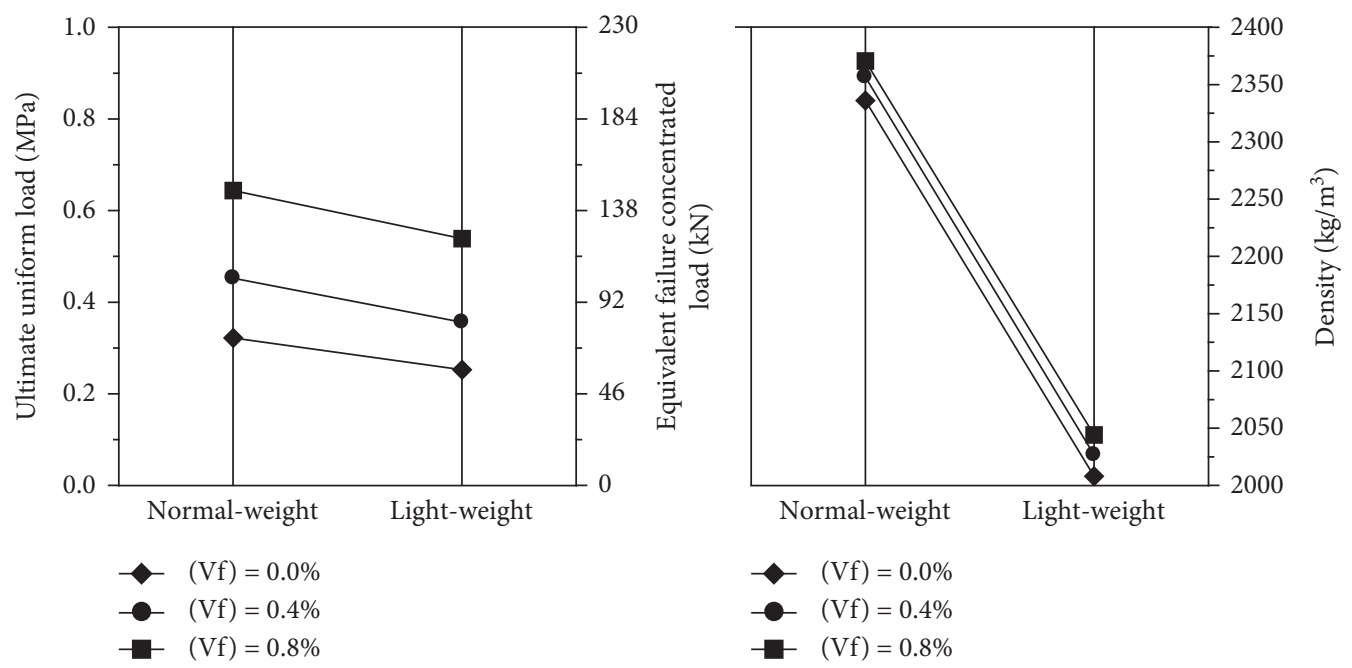

FIGURE 8: Effect of replacing normal-weight aggregate by lightweight aggregate on ultimate uniform load and density.

potential shear or tension cracks at the locations of their maximum stresses, the bad effect of the lightweight aggregate weakness will be negligible, and hence the ultimate failure load is increased for lightweight concrete by a higher percentage than for normal-weight concrete. Another reason might also contribute to this increase which is the roughness of the lightweight aggregate surface in comparison with that of the normal-weight aggregate. 


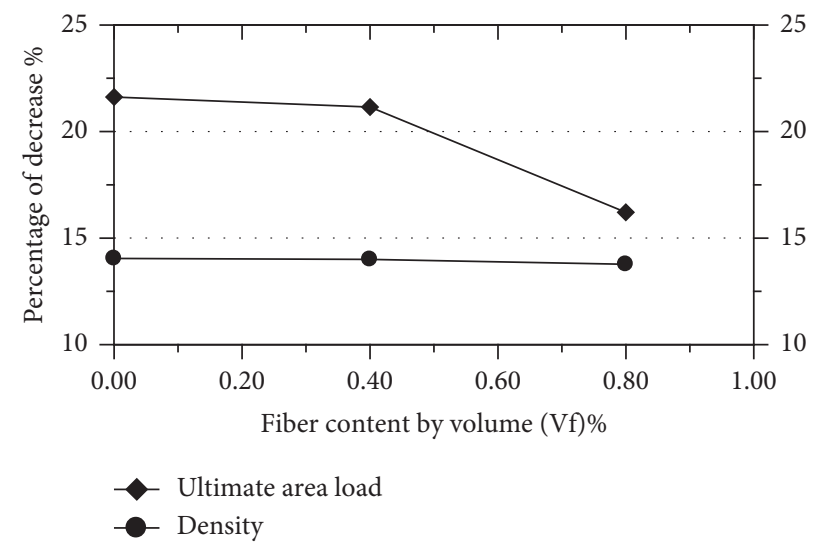

Figure 9: Percentage of decreasing in the ultimate uniform load and density when replacing normal-weight by lightweight aggregate.
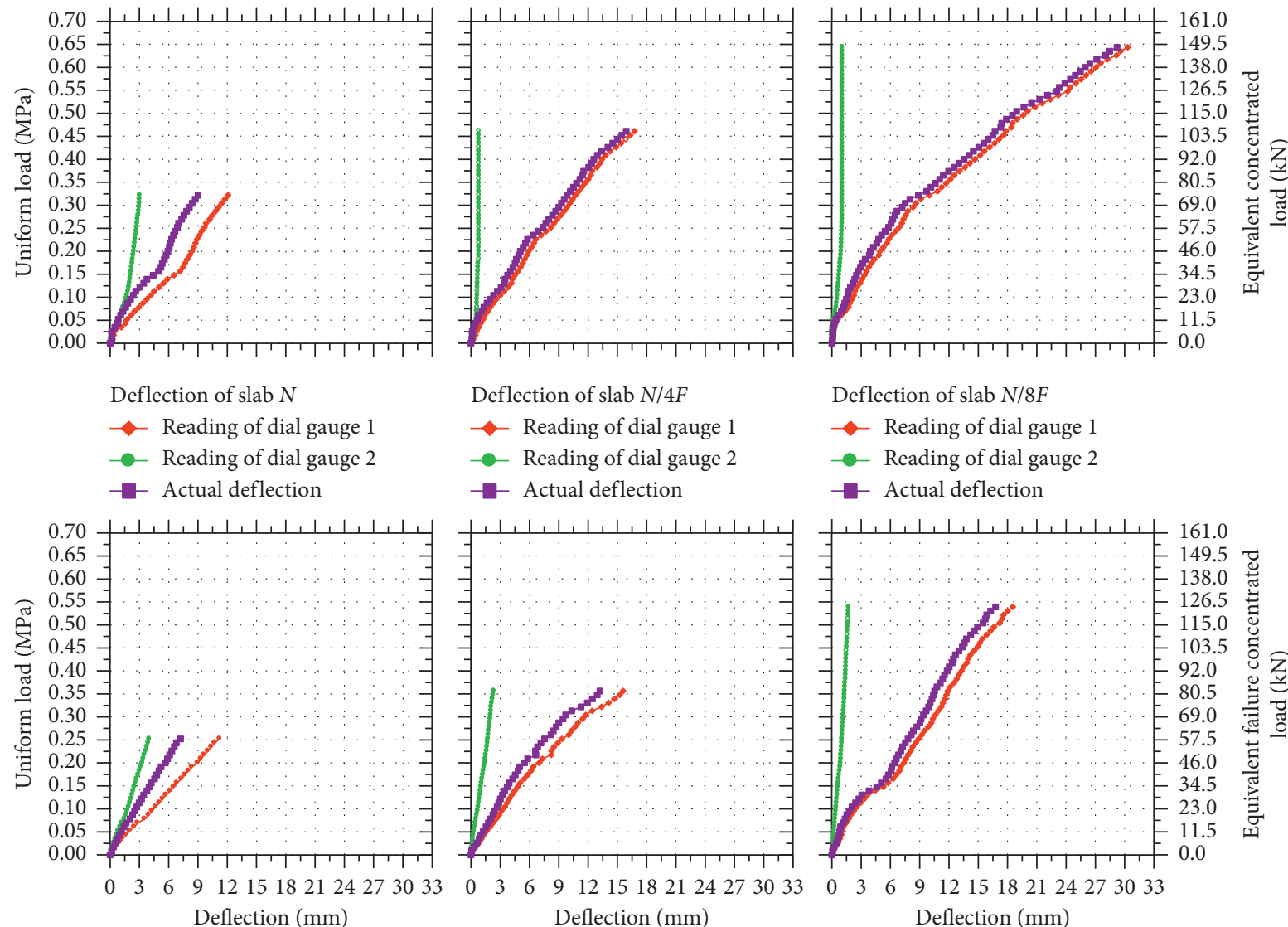

Deflection of slab N/8F

- Reading of dial gauge 1

- Reading of dial gauge 2

- Actual deflection

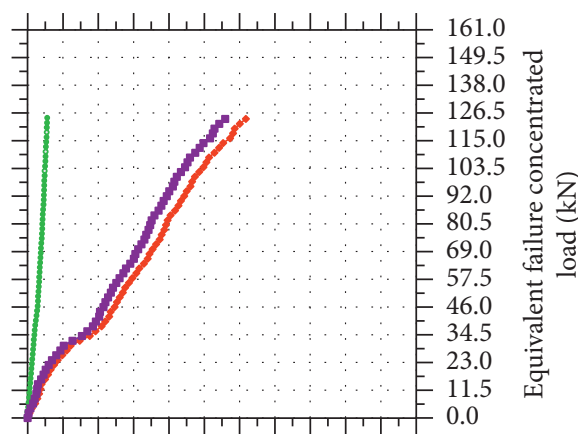
Deflection $(\mathrm{mm})$

Deflection $(\mathrm{mm})$

$\begin{array}{lllllllllll}0 & 3 & 6 & 9 & 12 & 15 & 18 & 21 & 24 & 27 & 3033\end{array}$

Deflection $(\mathrm{mm})$

Deflection of slab $L$

Deflection of slab $L / 4 F$

- Reading of dial gauge 1

- Reading of dial gauge 2

- - Actual deflection

- Reading of dial gauge 1

- Reading of dial gauge 2

- Actual deflection

Deflection of slab $L / 8 F$

- Reading of dial gauge 1

- Reading of dial gauge 2

- Actual deflection

Figure 10: Load-deflection curves for the normal-weight concrete slabs $(N),(N / 4 F)$, and $(N / 8 F)$ and lightweight concrete slabs $L,(L / 4 F)$, and $(L / 8 F)$.

6.2. Effect of Replacement of Normal-Weight Aggregate by Light-Weight Aggregate on Ultimate Uniform Load and Density. The effect of using porcelinite coarse aggregate (lightweight aggregate) in concrete as an alternative to natural river gravel (normal-weight aggregate) on the density and ultimate uniform load of concrete slabs with various steel fiber contents is illustrated in Figure 8 and Table 11.

This figure and table show that when replacing normalweight aggregate by lightweight aggregate, the density and ultimate uniform load are reduced. The percentages of this reduction in the ultimate uniform load are decreased with 


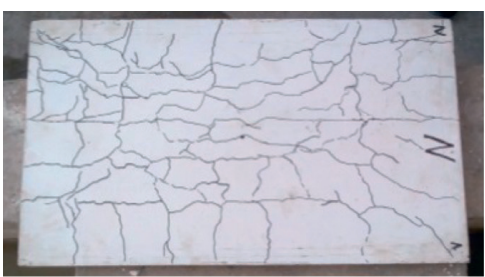

Slab $N$

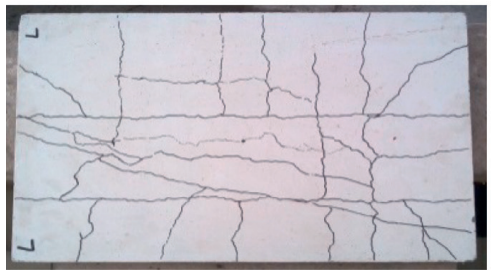

Slab $L$

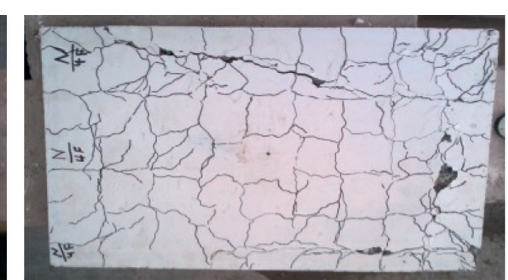

Slab $N / 4 F$

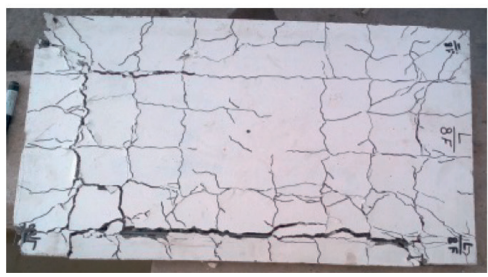

Slab $L / 4 F$

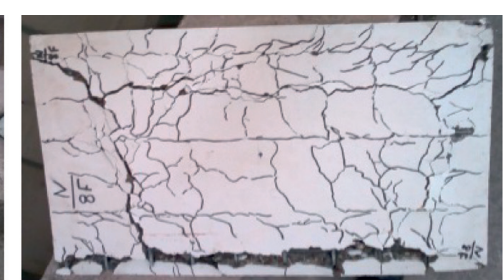

Slab $N / 8 F$

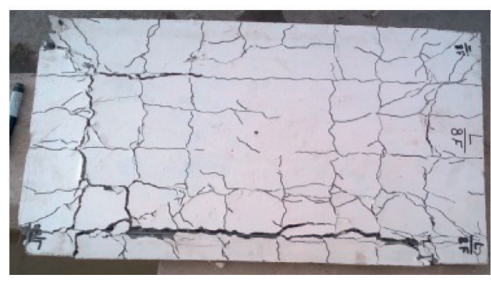

Slab $L / 8 F$

FIgURE 11: Bottom crack patterns at failure for all concrete slabs.

the increasing of steel fiber content. The reason for this behaviour might be because the percentage of increasing in the ultimate uniform load when steel fibers are added to the bottom layer of the slab is higher in lightweight than in normal-weight concrete, while the percentages of reduction in the density remain almost constant (Figure 9).

6.3. Load-Deflection Behaviour. Figure 10 shows the loaddeflection curves of the tested concrete slabs of groups 1 and 2 having normal-weight and lightweight aggregates, respectively, at the slabs center and at support edges for all load stages until failure occurs.

The net deflection at the slab center is the result of subtracting the deflection measured by the dial gauge at the support edge (dial gauge (2) reading) from the deflection measured by the dial gauge at slab center (dial gauge (1) reading at every loading stage) as shown in Figure 3. This subtraction is done because of the rubber pad laid under the slab edges where its deflection should not be counted.

Figure 10 also illustrates that when steel fiber content increases, the ultimate uniform load of slabs is increased and the deflection is slightly reduced. The reason for this behaviour may be because the presence of steel fibers prevents the initiation or at least reduces the growth of tension cracks and consequently increases the slab stiffness and hence decreasing deflection. This behaviour is similar for both types of concrete (normal-weight and lightweight concrete).

6.4. Modes of Failure and Crack Patterns. Figure 11 illustrates the crack patterns for the tested slabs for both concrete types: normal-weight (denoted by $N, N / 4 F$, and $N / 8 F$ ) and lightweight (denoted by $L, L / 4 F$, and $L / 8 F$ ).

For slabs not having steel fibers, i.e., $N$ and $L$, during the loading progress, cracks begin to initiate near corners and propagate diagonally until they intersect with the longitudinal crack near the center. A magnifying glass is used since most of the cracks are hair cracks and cannot be recognized by eye. When cracks were inspected and marked after the end of test, it was noticed that the obvious (apparent) cracks contain longitudinal cracks intersecting with diagonal ones (i.e., similar in shape with yield line cracks), which means that the failure mode was the bending mode.

When steel fiber was added with a $0.4 \%$ content, it was noticed that the crack numbers and widths in the bottom layer of slabs $(N / 4 F)$ and $(L / 4 F)$ were increased, especially shear type cracks which lead to conclude that the failure mode is the bending-shear mode.

Otherwise, when steel fiber content is increased to $0.8 \%$, the shear cracks numbers and widths in the bottom layer of slabs $(N / 8 F)$ and $(L / 8 F)$ were highly increased and lead to conclude that the mode of failure is shear type mode.

In the current work, it was noticed that with increasing steel fiber content, the failure mode is being altered from bending to shear; this may interpret that, when steel fiber content increases, the flexural strength of slab specimen increases higher than the shear strength, because almost all steel fibers (with any horizontal direction) serve to increase the bending strength in the maximum bending region (i.e., at the center), which leads to increase the flexural strength significantly, while at the shear region (near the support edges), steel fibers that are parallel and semiparallel to the support edge do not work to increase shear strength, so the improvement in shear strength is not significant.

\section{Conclusions}

The results of the current work had revealed the following:

(1) The addition of steel fiber to normal- and lightweight concretes with two volume fractions $(0.4 \%)$ and $(0.8 \%)$ for cubic and cylindrical specimens

(a) Increases the compressive strength, and the percentage of this increases is $16.3 \%$ and $24.9 \%$ in normal-weight concrete and $12.1 \%$ and $23.6 \%$ in lightweight concrete, respectively.

(b) Increases the tensile strength, and the percentage of this increase is $34.3 \%$ and $65.6 \%$ in normalweight concrete and $25 \%$ and $54.1 \%$ in lightweight concrete, respectively. 
(c) Increases the density, and the percentage of this increase is $1.7 \%$ and $2.9 \%$ in normal-weight concrete and $1.8 \%$ and $3.5 \%$ in lightweight concrete, respectively.

(d) From the results of the previous paragraphs (a), (b), and (c), one can notice that the percentage of increase in the compressive and split-tensile strengths of cubes and cylinders when steel fibers are added by $0.4 \%$ and $0.8 \%$ contents is noticed to be higher in normal-weight than in lightweight concrete, while the percentage of increase in the density due to this addition is higher in lightweight than in normal-weight concrete.

(e) When replacing normal-weight aggregate by lightweight in the cubic and cylindrical specimens, the density, compressive strength, and tensile strength are deteriorated. The percentage of deterioration in compressive strength and tensile strength increases with the presence of steel fiber content, but in density, the percentage of deterioration decreases with the presence of steel fiber.

(2) For normal-weight concrete slab specimens $(N, N$ / $4 F$, and $N / 8 F$ ) and lightweight concrete slab specimens $(L, L / 4 F$, and $L / 8 F)$ which have a volume fraction of steel fiber $\left(V_{f}\right)(0,0.4$, and 0.8$) \%$ in the bottom layer, respectively, when the steel fiber content is increased, the ultimate uniform load is considerably increased. The percentage of this increase is slightly higher for lightweight concrete slabs than for normal-weight concrete slabs. The results reveal that the percentage of increasing when the steel fiber is increased from $0 \%$ to $0.4 \%$ and to $0.8 \%$ equals $41.3 \%$ and $113.8 \%$ for lightweight concrete and $40.5 \%$ and $100 \%$ for normal-weight concrete, respectively.

(3) When replacing normal-weight aggregate by lightweight in the slabs, the density and the ultimate uniform load are deteriorated. The percentage of reduction in ultimate uniform load decreases with the increase of steel fiber content in the bottom layer of the slab. The results show that the percentage of decrease in density and ultimate uniform load was 14.04 and 21.62 for $V_{f}=0 \%, 14.00$ and 21.15 for $V_{f}=0.4 \%$, and 13.77 and 13.21 for $V_{f}=0.8 \%$, respectively.

(4) When steel fiber content is increased in the bottom layer of the slabs from $V_{f}=0 \%$ to $0.4 \%$ and to $0.8 \%$, the deflection of slab specimens is slightly reduced, and this behaviour is similar for both concrete types (normal-weight and lightweight).

(5) When steel fiber content is increased in the bottom layer of the slabs from $V_{f}=0 \%$ to $0.4 \%$ and to $0.8 \%$, the flexural strength is increased higher than shear strength; therefore, the mode of failure has changed from bending to shear mode, and this behaviour is similar for both concrete types (normal-weight and lightweight).

\section{Data Availability}

The data used to support the findings of this study are available from the corresponding author upon request.

\section{Conflicts of Interest}

The authors declare that they have no conflicts of interest.

\section{Acknowledgments}

The authors wish to acknowledge Mustansiriyah University, Baghdad, Iraq (http://www.uomustansiriyah.edu.iq).

\section{References}

[1] A. Ellouze, M. Ouezdou, and M. A. Karray, "Experimental study of steel fiber concrete slabs Part I: behavior under uniformly distributed loads," International Journal of Concrete Structures and Materials, vol. 4, no. 2, pp. 113-118, 2010.

[2] S. Juradin, G. Baloevica, and H. Alene, "Experimental testing of the effects of fine particles on the properties of the selfcompacting lightweight concrete," Advances in Materials Science and Engineering, vol. 2012, p.8, 2012. Article ID 398567.

[3] F. Tomosawa, "Special HPCS II: "lightweight aggregate HPC, self-compacting HPC," in Fourth International Symposium on the Utilization of High Strength/High Performance Concrete, F. de Larrard and R. Lacrix, Eds., Vol. 1, Pr. Ponts et Chaussées, Paris, France, 1996.

[4] F. A. Mirza and P. Soroushian, "Effects of alkali-resistant glass fiber reinforcement on crack and temperature resistance of lightweight concrete," Cement and Concrete Composites, vol. 24, no. 2, pp. 223-227, 2002.

[5] P. Soroushian, M. Nagi, and J. Hsu, "Optimization of the use of lightweight aggregate in carbon fiber reinforced cement," ACI Materials Journal, vol. 89, no. 3, Article ID 26776, 1992.

[6] P. K. Mehta and P. J. M. Monteiro, Concrete; Microstructure, Properties, and Materials, McGraw-Hill Education, New York, NY, USA, 3rd edition, 2006.

[7] V. C. Li, "Large volume, high-performance applications of fibers in civil engineering," Journal of Applied Polymer Science, vol. 83, no. 3, pp. 660-686, 2002.

[8] J. Edgington, D. J. Hannant, and R. I. T. Williams, "Steel fibre reinforced concrete," Build Res EstabCurr Pap, CP, vol. 69, no. 74, pp. 154-170, 1974.

[9] S. Kim and C. Park, "Flexural behavior of high-volume steel fiber cementitious composite externally reinforced with basalt FRP sheet," Journal of Engineering, vol. 2016, Article ID 2857270, 9 pages, 2016.

[10] A. S. D. Al-Ridha, "The influence of size of lightweight aggregate on the mechanical properties of self-compacting concrete with and without steel fiber," International Journal of Structural and Civil Engineering Research, vol. 3, no. 1, pp. 54-68, 2014.

[11] A. S. D. Al-Ridha, A.K. Ibrahim, H. M. Al-Taweel, and L. S. Dheyab, "Effect of steel fiber on ultrasonic pulse velocity and mechanical properties of self-compact light weight concrete," IOP Conference Series: Materials Science and Engineering, 2, vol. 518, pp. 1-12, 2019.

[12] L. A. Al-Jabri, "The Influences of Mineral Admixtures and Steel Fibers on the Fresh and Hardened Properties of SCC," 
M. Sc. thesis, University of Al-Mustansirya University, Baghdad, Iraq, 2005.

[13] F. P. Álvarez Rabanal, J. Guerrero-Muñoz, M. Alonso-Martinez, and J. E. Martinez-Martinez, "Bending and shear experimental tests and numerical analysis of composite slabs made up of lightweight concrete," Journal of Engineering, vol. 2016, Article ID 6819190, 10 pages, 2016.

[14] N. A. Libre, M. Shekarchi, M. Mahoutian, and P. Soroushian, "Mechanical properties of hybrid fiber reinforced lightweight aggregate concrete made with natural pumice," Construction and Building Materials, vol. 25, no. 5, pp. 2458-2436, 2012.

[15] M. Hassanpour, P. Shafigh, and H. B. Mahmud, "Lightweight aggregate concrete fiber reinforcement-a review," Construction and Building Materials, vol. 37, pp. 452-461, 2012.

[16] C. E. Chalioris, C. P. Papadopoulos, C. N. Pourzitidis, D. Fotis, and K. K. Sideris, "Application of a reinforced selfcompacting concrete jacket in damaged reinforced concrete beams under monotonic and repeated loading," Journal of Engineering, vol. 2013, p. 12, 2013. Article ID 912983.

[17] EFNARC, "Specification and guidelines for self-compacting concrete," EFNARC, London, UK, 2002.

[18] Iraqi Specifications No. 45/1984, Aggregate of the Natural Sources Used in Concrete Construction, Central Organization for Standardization and Quality Control, Baghdad, Iraq, 1980.

[19] ASTM, ASTM C33/C33M-18 Standard Specification for Concrete Aggregates, ASTM International, West Conshohocken, PA, USA, 2011.

[20] K. S. M. Bassam, D. Hagopian, and N. Al-Sadi, Geological Investigation of the Traifawi Montamorillon Clay-Stone Deposite Waste. Geosurv. Internal Report, 1986.

[21] ASTM, Standard Test Method for Specific Gravity and Adsorption of Coarse Aggregate, p. 127, ASTM, West Conshohocken, PA, USA, 2000.

[22] ASTM, C29 Standard Test Method for Bulk Density ("Unit Weight") and Voids in Aggregate, American Society for Testing and Materials, West Conshohocken, PA, USA, 2017.

[23] ASTM: C-330-2006, Standard Specification for Lightweight Aggregates for Structural Concrete, ASTM International, West Conshohocken, PA, USA, 2006.

[24] W. H. Taylor, Concrete Technology and Practice, McGra Hill Education, Philadelphia PA, USA, 4th edition, 1977.

[25] American Concrete Institute Committee 211, Standard Practice for Selecting Proportions for Structural Lightweight Concrete (ACI211. 2-81), American Concrete Institute, Detroit, MI, USA, 1981.

[26] D. J. Hannant, Fiber Cement and Fiber Concrete, John, Wiley and Sons, Hoboken, NJ, USA., 1978.

[27] R. Knott, "Fibonacci and golden ratio formulae," 2016, http:// www.maths.surrey.ac.uk/hosted-sites/R.Knott/Fibonacci/ fibFormulae.html.

[28] ASTM A370, Standard Test Method and Definitions for Mechanical Testing of Steel Products, ASTM International, West Conshohocken, PA, 2014.

[29] A. S. Al-Ridha, A. F. Atshan, K. S. Mahmoud, and Q. K. Hameed, "Effect of strengthening of steel beams with variable length by using carbon fiber," Journal of Engineering, vol. 2019, Article ID 1631692, , 2019.

[30] A. S. Al-Ridha, Q. K. Hameed, A. F. Atshan, A. A. Abbood, and L. S. Dheyab, "Evaluation of strengthening steel beams using the technique of carbon fiber confinement by a steel plate (CFCSP)," Advances in Civil Engineering Materials, vol. 9, no. 1, pp. 53-66, 2020.

[31] JSCE, Recommendation for Self-Compacted Concrete, TokyoJapan Society of Civil Engineers, Tokyo, Japan, 1999.
[32] BS 1881 Part 116, Method for Determination of Compressive Strength of Concrete Cubes, British Standards Institution, London, UK, 1989.

[33] ASTM International, Standard Test Method for Splitting Tensile Strength of Cylindrical Concrete Specimens, ASTM International, West Conshohocken, PA, USA, 2017. 